\section{OBSTÁCULOS NO ENSINO DE MATEMÁTICA: O POSICIONAMENTO DE PROFESSORES DE MATEMÁTICA SOBRE A FONTE DE OBSTÁCULOS DURANTE A APRESENTAÇÃO DO TEMA PROBABILIDADE}

\author{
Wanderley Pivatto Brum ${ }^{1}$ \\ Sani de Carvalho Rutz da Silva ${ }^{2}$
}

\begin{abstract}
RESUMO: Apresentamos os resultados de uma investigação com o objetivo de analisar os posicionamentos de seis professores de Matemática no município de Tijucas, Santa Catarina sobre obstáculos no ensino de Matemática durante a apresentação em sala de aula sobre o tema probabilidade. Para a coleta de dados, utilizamos entrevistas semiestruturadas e a técnica de complemento. Para as análises, definimos três unidades: a natureza de obstáculo, fontes de obstáculos e atitudes dos professores de Matemática em situações de tensão. De maneira geral, constatamos que os professores apresentam aspectos importantes que caracterizam a importância do tema probabilidade na prática docente, como o questionamento, valorizando, por exemplo, as situações práticas do cotidiano. Entretanto, alguns ainda parecem ter uma compreensão parcial de obstáculo e suas possíveis fontes para o ensino de Matemática, não explicitando aspectos importantes, como seu posicionamento crítico e reflexivo sobre o uso desse conhecimento. Percebemos que eles apresentam noções sobre o "reconhecimento do obstáculo", no entanto ainda encontram dificuldades em efetivar nas salas de aula, junto com seus estudantes, um processo de (re)construção dos conceitos matemáticos.
\end{abstract}

Palavras-chave: Ensino de matemática. Obstáculos. Probabilidade.

\section{OBSTACLES IN THE TEACHING OF MATHEMATICS: THE POSITIONING OF TEACHERS OF MATHEMATICS ON THE SOURCE OF OBSTACLES DURING THE PRESENTATION OF THE PROBABILITY}

\begin{abstract}
We present the results of an investigation with the objective of analyzing the positions of six teachers of Mathematics in the municipality of Tijucas, Santa Catarina on obstacles in the teaching of Mathematics during the classroom presentation on the theme probability. To collection data, we used semi-structured interviews and the technique of supplement. For the analyzes, we defined three units: the nature of obstacle, sources of obstacles and attitudes of teachers of Mathematics in situations of tension. In general, we found that the teachers are important aspects that characterize the importance of the topic probability in teaching practice, such as the questioning, valuing, for example, the situation practices of

\footnotetext{
${ }^{1}$ Universidade Federal de Santa Catarina - UFSC (SC). Doutorando em ensino de Ciência e Tecnologia pela UTFPR/PR. Email: ufsc2013@yahoo.com.br

${ }^{2}$ Universidade Tecnológica Federal do Paraná - UTFPR (PR). Dra. em Engenharia de Materiais pela UFRGS. Professora do quadro permanente do PPGECT da Universidade Tecnológica Federal do Paraná, UTFPR, PR. Email: sani@utfpr.edu.br
} 


\section{(atinerarius

everyday life. However, some people still seem to have a partial understanding of obstacle and its possible sources for the teaching of Mathematics, not explaining important aspects, such as its positioning critical and reflective about the use of this knowledge. We noticed that they have notions about the "recognition of the obstacle", however still find it difficult to commit to the classroom, along with their students, a process of (re)construction of mathematical concepts.

Keywords: Mathematics education. Obstacles. Probability.

\section{INTRODUÇÃO}

Atualmente, questões envolvendo dificuldades de aprendizagem em conteúdos de Matemática tem sido objeto de pesquisas, palestras e encontros, com o objetivo de avaliar e apontar possíveis origens para diversos problemas no ensino de Matemática (Perrrenoud, 2005), (Garbi, 2009), (D’ambrósio, 2009), (Mendes, 2011), (Coll, 2012), entre outros.

Entre as diversas dificuldades que possam surgir durante o processo de aprendizagem, Coll (2012) alerta para o grande número de diversidade encontrada em sala de aula, indicando a existência de "vários mundos quantos forem as pessoas lá presentes", com diversificado quadro de valores, crenças, expectativas e ansiedades, onde cada uma carrega sua história, sua classe social, seu tipo físico, sua participação em grupos exclusivos, onde as vezes apresentam própria linguagem.

Na tentativa de minimizar as dificuldades encontradas pelos alunos, os professores em função de seu papel institucional de formação, comumente utilizam em sala de aula diversas estratégias com o intuito de facilitar a aprendizagem. Entre as estratégias, destacam-se as analogias, metáforas, imagens, resolução de problemas, desafios entre outras. Ainda que empregadas com a intenção de contribuir para a compreensão de determinado conteúdo, as estratégias se caracterizam como subterfúgios pedagógicos, substituindo assim, linhas de raciocínio por esquemas e macetes, o que se por um lado se torna atrativo de interesse, por outro se cristaliza intuições (Luckesi, 2000).

A partir dessa breve explanação sobre as dificuldades que se apresentam para os alunos em seu processo de aprendizagem e os desafios enfrentados pelos professores em sua prática docente, o objetivo desse artigo é apresentar os resultados da investigação desenvolvida junto a professores de Matemática da rede pública de Tijucas, Santa Catarina, com relação ao tema obstáculos no ensino de Matemática, com enfoque na abordagem probabilidade. 


\section{(tzinerarius

$$
\text { v.11, n. } 1,2015
$$

\section{A NATUREZA DOS OBSTÁCULOS}

Do latim obstacùlum, significa impedimento, empecilho, resistência, algo que impede ou atrapalha o movimento, a progressão de alguém ou alguma coisa (Houaiss, 2007). Um obstáculo na aprendizagem ou no avanço das ideias, é para Brousseau (2007), uma concepção ou conhecimento que, no momento de sua formação foi eficiente, mas que se revela inadequado quando na tentativa de aplicação em novas situações. Dado o êxito obtido anteriormente, apesar dos fracassos, tende-se a conservar a ideia que parece comprovada. Esse fato acaba tornando-se uma barreira para novas aprendizagens. Na visão de Lecourt (2000), os obstáculos preenchem a ruptura entre o conhecimento comum e o conhecimento científico e restabelece a continuidade ameaçada pelo progresso do conhecimento científico e podem aparecer na forma de um contra pensamento ou como paragem do pensamento. São compreendidos como resistências do pensamento ao pensamento (metapensamento).

Segundo Bachelard (2008), não se tratam de obstáculos externos, como a complexidade e a fugacidade dos fenômenos, nem de incriminar a fragilidade dos sentidos e do espírito humano. É no âmago do próprio ato de conhecer que aparecem, por uma espécie de imperativo funcional, lentidões e conflitos. Os conflitos provocam a desistência por parte do aluno em solucionar um problema matemático, afirmando não ter aprendido como resolver aquele tipo de questão ainda, quando ele não consegue reconhecer qual o algoritmo ou processo de solução apropriado para aquele problema. Falta aos alunos uma flexibilidade de solução e a coragem de tentar soluções alternativas, diferentes das propostas apresentadas pelos professores.

Lopes (2005) relembra que o processo de negação de um conhecimento não implica na destruição total dos conhecimentos anteriormente estabelecidos e fim de um obstáculo, mas ir além desses conhecimentos, reordená-los e introduzi-los em uma nova ordem de racionalidade. Um bom exemplo é a Teoria Newtoniana que em momento algum foi negada pela Teoria Einsteiniana, mas limitada em um conceito de espaço e tempo muito inferior ao limite englobado pela nova Teoria da Relatividade.

$\mathrm{Na}$ interpretação de Kummer (1999), a teoria bachelardiana prevê que todo o saber científico deve ser reformulado, pois assim a ciência se mostrará viva, pois se reconstrói através da superação dos obstáculos, que emergem como uma tentativa de impedir a ascensão ao conhecimento. Quando os obstáculos são superados é que chegamos à verdade. Para Bachelard (2008), a opinião é um dos obstáculos a ser superado. A ciência é contra a opinião, pois a opinião 


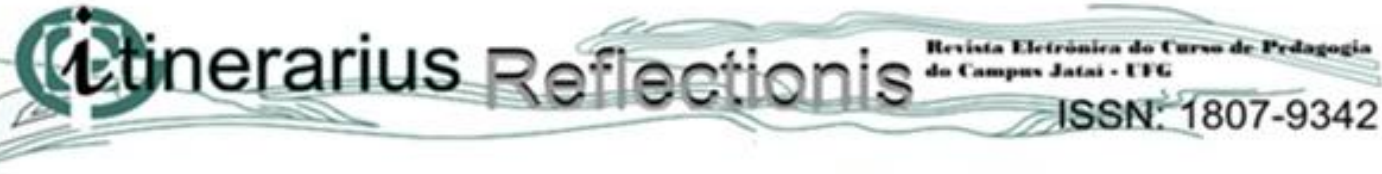

v.11, n. 1,2015

pensa mal, não pensa: traduz necessidades em conhecimento. Não se pode opinar sobre aquilo que não sabemos. Deve-se sim, buscar conhecimentos para superar essa fragilidade. Desta forma, o verdadeiro espírito científico é aquele que se opõe, questiona e pergunta. Todo novo conhecimento é uma resposta para uma pergunta.

Ao longo da história, diversos filósofos e epistemólogos buscaram analisar e compreender como ocorre o processo de produção do conhecimento científico e apropriação pelos seres humanos. Dois pensadores modernos que trouxeram luz sobre os obstáculos que emergem durante o processo de aprendizagem e que contribuíram para esse trabalho foram Gaston Bachelard (2008) e Guy Brousseau (2007), que compreendem o ato de conhecer como um ato de negação e realizam uma reflexão sobre três possíveis fontes para o surgimento de obstáculos durante o processo de aprendizagem de um conteúdo. Com relação ao obstáculo cuja fonte é de cunho ontogenético, este encontra-se relacionado às próprias capacidades cognitivas dos alunos, de acordo com o seu desenvolvimento. Muito desse obstáculo, deve-se ao fato dos professores não levarem em consideração o conhecimento que os estudantes já possuem e por conceberem a aquisição do novo conhecimento como um acúmulo, que pode ser obtido simplesmente por mera repetição (Brousseau, 2007).

As pesquisas de Freitas (2002) no campo da probabilidade apontam a idéia de uma matemática exata fechada como a ciência dos números, dos resultados precisos acabam muitas vezes servindo de obstáculo epistemológico para o entendimento do significado de fenômenos aleatórios, fenômenos pelos quais justificam a teoria das probabilidades. Por outro lado, Fricke e Veit (2003) apontaram em suas investigações que as principais dificuldades percebidas nas/pelas professoras em relação aos conceitos probabilísticos eram obstáculos epistemológicos e sobre o ensino destes obstáculos didáticos e epistemológicos no ensino de noções de análise combinatória, probabilidades e estatística, conceitos estes estudados nos anos iniciais e finais do Ensino Fundamental. Takis (2000) cita que é importante realizar um diagnóstico na tentativa de identificar se os alunos com dificuldades de aprendizagem de matemática diferem quanto aos conceitos, habilidades e execuções em relação aos seus companheiros de igual ou menor idade, sem dificuldades de aprendizagem.

É bastante comum o aluno desistir de solucionar um problema matemático, afirmando não ter aprendido como resolver aquele tipo de questão ainda, quando ele não consegue reconhecer qual o algoritmo ou processo de solução apropriado para aquele problema. Na pesquisa de Igliori 


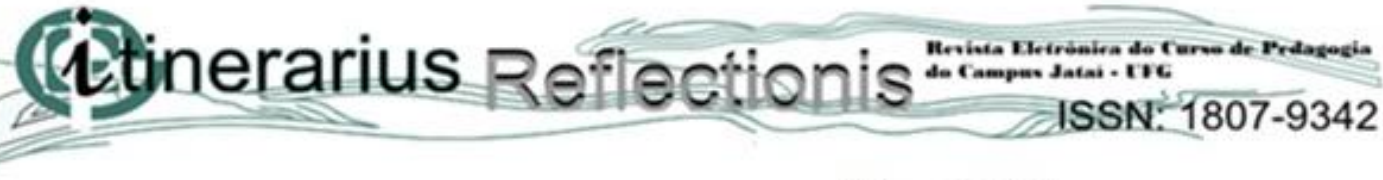

v.11, n. 1,2015

(2002), o autor constata que os alunos trazem contribuições e carregam uma bagagem que deve ser (re)conhecida no processo de ensino pelo professor, cabendo a ele desenvolver recursos que captem o conhecimento prévio do aluno acerca do assunto a ser estudado. Na visão de D’Amore (2007), o obstáculo que surge e reforça a dificuldade de aprendizagem em Matemática pode se manifestar em relação ao desenvolvimento cognitivo e à construção da experiência matemática, do tipo da conquista de noções básicas e princípios numéricos, da conquista da numeração, quanto à prática das operações básicas, quanto à mecânica ou quanto à compreensão do significado das operações. Os resultados de pesquisas de Lopes (2003) apontam para a potencialidade de se trabalhar noções de probabilidade e estatística desde a educação infantil. Essa autora entende que a inclusão de noções de probabilidade, desde os anos iniciais do ensino fundamental, pode se tornar um dos meios para a construção de um pensamento não determinístico, evitando possíveis obstáculos epistemológicos.

Ao tratar sobre os obstáculos didáticos, Brousseau (2007) explicita que os mesmos são conhecimentos incorporados no cotidiano do ensino-aprendizagem e que permitem a produção de respostas adaptadas a certos problemas, mas podem conduzir a respostas errôneas a diversos tipos de questionamentos, podendo apresentar resistência a modificações ou transformações. Bachelard (2008) cita que a manifestação do obstáculo didático ocorre de maneira reincidente e a sua rejeição representa uma ruptura com o conhecimento anterior e, consequentemente, por meio dos atos pedagógicos, a formação de novo conhecimento. A reflexão de Bachelard (2008) é defendida por Costa (2003), ao explicitar as barreiras existentes (fragmentação) entre as disciplinas, os obstáculos metodológicos, os obstáculos quanto à formação, os obstáculos materiais etc.

Tais obstáculos didáticos podem ser criados pelo próprio professor ao escolher uma determinada estratégia de ensino que não favoreça plenamente a construção do conhecimento científico (Brousseau, 2007). Uma das consequências é que o próprio professor pode tornar-se um obstáculo na formação específica de seus alunos. Nesse sentido, a formação específica dos professores exige uma abordagem mais ampla e consistente, pois dominar o conteúdo específico é importante, mas não é suficiente para ser um bom professor, sendo necessário conhecer como o aluno aprende e como agir para facilitar a aprendizagem.

Segundo Gomes (2007), a ausência dessa postura de investigação por parte professor constitui um obstáculo didático, fato que pode ocorrer quando a atuação do professor se pauta 


\section{(Stionerararus 20 2

$$
\text { v.11, n. } 1,2015
$$

numa perspectiva tradicional. Nesse sentido, a ausência de formação pedagógica pode levar os professores ao desenvolvimento de uma prática que reflete os tempos de estudante, procurando imitar a prática dos mestres que lhes serviram de modelo, reforçando a cultura de uma prática milenar, a do ensino dogmático.

A ideia de Bachelard (2008) transita na possibilidade do professor provocar rupturas em relação ao conhecimento cotidiano que o aluno traz para o ambiente escolar, modificando o foco em suas aulas, fazendo com que os alunos não permaneçam apenas no fato, na intuição, no empírico. É necessário, portanto, o rompimento com o superficial adotando a atitude científica para a construção do conhecimento científico. Brousseau (2007) reforça a ideia de Bachelard (2008), quando explicita que os obstáculos didáticos se originam por alguma ação educativa, didática ou do sistema educativo, ou seja, uma ação externa do professor ou um projeto de ensino que possibilita um conceito errado, como consequência das relações escolhidas para serem trabalhadas com um determinado conceito.

Lukács (2004) aponta que Brousseau introduz a noção de obstáculo didático em Didática da Matemática como sendo aquele obstáculo ligado à resistência de um saber mal adaptado, no sentido de Bachelard (2008) e o vê como um meio de interpretar alguns dos erros recorrentes e não aleatórios cometidos pelos estudantes, quando lhes são ensinados alguns tópicos da Matemática. Segundo Pais (2008), os obstáculos didáticos são conhecimentos que se encontram relativamente estabilizados no plano intelectual e que podem dificultar a evolução da aprendizagem do saber escolar. É preciso, portanto, compreender como ocorre a reorganização dos conhecimentos matemáticos para que estes entrem em harmonia com os demais já existentes, sendo esse o momento em que os obstáculos se manifestam.

Bachelard (2008) afirma que a noção de obstáculo epistemológico pode ser estudada no desenvolvimento histórico do pensamento científico e na prática da educação. Para encontrar estes obstáculos, Brousseau (2007) define um método de pesquisa que consiste em três fases: a) encontrar erros sistemáticos e concepções em torno das quais esses erros se agrupam; b) encontrar obstáculos na história da matemática; c) confrontar os obstáculos históricos com os obstáculos na aprendizagem. Com relação aos obstáculos epistemológicos, podem ser encontrados no decorrer da História da Matemática, durante sua construção histórica, na qual se constituíram em barreiras, algumas das quais demoraram anos, décadas e até séculos para serem superadas. Estas formas limitadas do conhecimento de um determinado conceito continuam a se 
manifestar durante o aprendizado do aluno, na disciplina de Matemática. Bachelard (2008) desenvolve a ideia de obstáculos epistemológicos argumentando sobre existência de cinco obstáculos:

Obstáculo da Experiência Primeira: descrito como o obstáculo relacionado com o conhecimento já adquirido pelo aluno acerca dos temas estudados, ou seja, como as ideias e explicações populares entendem os fenômenos. É um dos mais importantes, uma vez que o conhecimento científico só é criado quando contraposto ao conhecimento prévio (Bachelard, 2008). Leite et al. (2006) entendem que a experiência primeira está relacionado com impressões prévias no campo concreto colocadas antes e acima da crítica de determinados assuntos.

Obstáculo Animista: esse obstáculo surge quando são atribuídas características próprias de seres vivos a objeto de estudos, não-vivos, abordados pela química (Mortimer, 2000). Como a descrição de catálise, apresentada por Lopes (2005), que afirmava que "o catalisador acelerava o processo, pois despertava, devido a sua presença, afinidades adormecidas”, descrição que delega aos compostos características inerentes de seres vivos.

Obstáculo Realista: essa dificuldade surge quando o aluno se contenta com a explicação concreta de um fenômeno, não conseguindo promover a abstração necessária para obter uma explicação completa. De maneira mais aplicada, esse fenômeno ocorre, como cita Bachelard (2008), quando não se consegue abstrair as explicações microscópicas dos fenômenos, somente as macroscópicas. Como, por exemplo, o caso a seguir que mostra uma representação de distorções conceituais e representacionais relativas aos modelos atômicos cientificamente aceitos, pois, segundo a qual, o átomo pode ser segurado, visto a olho nu e ainda perfurada com uma furadeira (Leite et al., 2006).

Obstáculo Substancialista: esse obstáculo pode ser observado quando, na explicação dos fenômenos, substitui-se a explicação correta do fenômeno pela análise das características substanciais, por exemplo, atribuir a acidez somente à presença de hidrogênios ionizáveis na molécula (Bachelard, 2008). Ou quando se tenta explicar um fenômeno de forma simplificada, mas incoerente. A título de exemplo, a situação seguinte na qual se explica a acidez dos compostos exclusivamente pela presença de hidrogênios ionizáveis (prótons), o que não é correto, pois existem outros tipos de interações com o ânion e com a água, por exemplo, que determinam a força do ácido (Lopes, 2005). 


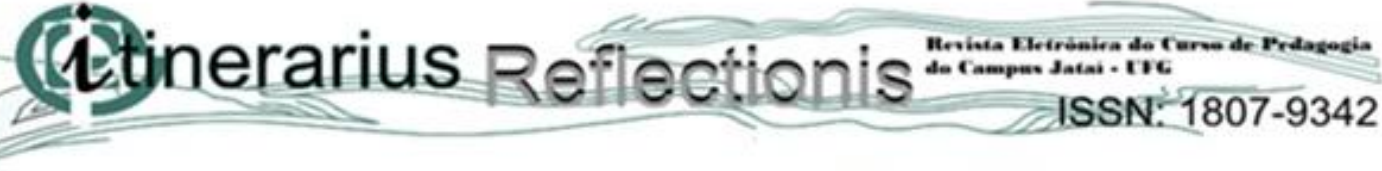

v.11, n. 1,2015

Obstáculo verbal: esse obstáculo aparece quando são utilizados termos do senso comum, do cotidiano ou analogias, para tentar facilitar a compreensão de um fenômeno. Essa prática, além de impedir que o conceito seja aprendido da forma correta, por ir contra ao obstáculo da experiência primeira, pode levar à elaboração de concepções alternativas por parte do aluno (Bachelard, 2008).

Pietrocola (2004) apresenta a ciência que não desvela truísmos. Ao contrário, faz parte da grandeza e da beleza da ciência o fato de podermos aprender, através de momento de tensão e investigações conduzidas pelo espírito crítico (Bachelard, 2008), que o mundo é inteiramente diverso daquilo que chegamos a imaginar, até que a nossa intuição e imaginação seja reformulada pela refutação de teorias anteriores. Quanto ao ensino de Matemática face a evolução detectada ao largo da história, D’Ambrósio (2009) destaca que tal processo formal de ensino não pode ficar alheio a essa nova forma de conceber a matemática. Para Delizoicov e Angotti (2006), as mudanças a serem feitas na escola devem seguir o mesmo sentido desta nova ideia de ciência, ou ela correrá o risco de preparar os estudantes para um futuro inexistente, preparando de forma inadequada para as necessidades da sociedade na qual terão de viver. Com isso, muito do espírito de uma ciência com a visão arcaica, cujas lutas no campo do conhecimento impunham a razão do mais forte, chegando à eliminação física do adversário, ainda perdura na ciência atual e no seu ensino nas escolas (Brum, 2014).

Como antídoto a essa sintomática, o professor apresenta-se como agente humano que na sala de aula precisará decidir, e a sua decisão pode modificar a existência dos outros e do mundo (Delizoicov; Angotti, 2006). Uma decisão, portanto, que não ocorre sem sofrimento, sem tensão, pois exige a escolha numa situação repleta de ambiguidades e dilemas, com diferentes respostas possíveis e discursos ideológicos. Diante desse pressuposto e da complexidade do tema, a nossa preocupação limita-se, a partir de agora, a assuntos relacionados ao ensino de Matemática, dentre os quais o tema "probabilidade" foi escolhido porque é gerador de grandes contribuições em diversas áreas do conhecimento.

Reportamos ao caso "A religião como erro lógico", publicado na revista Veja de 2008, onde o professor John Allen Paulos, 62 anos, catedrático da Universidade Temple, na Filadélfia, se esforça para ensinar a matemática como uma forma de pensamento, um molde rigoroso mas criativo para o exame do mundo. Irreligion é um livro devotado à lógica: Paulos analisa argumentos tradicionais sobre a existência de Deus e mostra onde fazem água. Autor de uma 


\section{(cibnerarius 20

coluna em que examina aspectos matemáticos dos eventos do cotidiano no site da rede de televisão ABC, Paulos ganhou popularidade com Innumeracy (traduzido no Brasil como Analfabetismo em Matemática e Suas Consequências, em edição esgotada), livro em que alertava para as armadilhas da falta de familiaridade com números.

$\mathrm{Na}$ perspectiva da ciência, em diversas publicações, editadas e divulgadas por alguns cientistas, não são raras as citações de aceitação e negação no uso de equações matemáticas para comprovar a existência de diversos mundos, teorias e conspirações. No exemplar de junho de 2014, a revista Galileu publicou um artigo que no dia 13 de julho, o Maracanã vai ser palco do que promete ser o maior confronto futebolístico de todos os tempos: uma final de Copa do Mundo entre Brasil e Argentina. Pelo menos é o que defendem os estatísticos da USP e UFSCar que fazem parte do Grupo de Modelagem Estatística no Esporte (GMEE) - na Copa de 2010, eles acertaram que a final seria disputada por Espanha e Holanda, e também cantaram a bola de que a Espanha levaria o título. Basicamente, o modelo agrega informações de 18 sites de apostas, além de levar em consideração os placares das partidas ao longo do torneio. Os estatísticos também calculam as probabilidades para os times nos campeonatos inglês, espanhol e brasileiro.

Por outro lado, Lopes (2005) enfatiza que vivemos dias envoltos em problemas econômicos, muita violência, desemprego, fome, um sistema de saúde extremamente precário, escolas e universidades bem próximas de total abandono. É diante desse potencial cenário que o ensino da Estatística e da Probabilidade se insere, fazendo emergir discussões sobre sua relevância na formação do aluno durante a escola básica. Essa temática tem sido alvo de pesquisas em algumas partes do mundo, e muitos pesquisadores publicam trabalhos a respeito, procurando justificar essa relevância.

De acordo com os Parâmetros Curriculares Nacionais para o ensino de Matemática (Brasil, 1998), o pensamento probabilístico é introduzido como elemento auxiliar, tanto na aprendizagem de matemática quanto na interpretação dos fatos divulgados pelos meios de comunicação. A principal finalidade da probabilidade é a de que o aluno compreenda que muitos dos acontecimentos do cotidiano são de natureza aleatória e que se pode identificar possíveis resultados desses acontecimentos e até estimar o grau de possibilidade acerca do resultado de um deles. Neste sentido apresentamos os resultados parciais de uma pesquisa desenvolvida com professores de Matemática, a partir das seguintes questões de investigação: Quais as concepções dos professores sobre obstáculos, obstáculos no ensino de Matemática e probabilidade? Quais os 


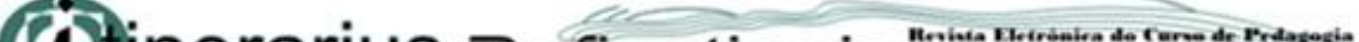 20. 2

discursos apesentados pelos professores para o ensino de probabilidade em sala de aula? Que atitudes são fomentadas pelos professores na apresentação de temas que caracterizam tensão?

\section{CONTEXTO E ASPECTOS METODOLÓGICOS}

Os sujeitos investigados foram escolhidos levando em consideração dois fatores: formação em Matemática; experiência entre 5 a 15 anos em sala de aula. Os sujeitos são seis professores de Matemática na rede estadual de Ensino de Tijucas. Desse conjunto, todos têm pós graduação (lato sensu). Para participar da investigação, o pesquisador compareceu nas escolas e com autorização do diretor, conversou com os professores. Por se tratar de uma entrevista, o TCLE (termo de consentimento livre e esclarecido) foi assinado pelos professores investigados.

Para identificar e analisar as concepções que os professores de Matemática possuem sobre a natureza de obstáculos, suas principais fontes e seus posicionamento em momentos de tensão na apresentação do tema probabilidade, utilizamos como instrumentos de coleta de dados a Técnica de Complemento, que consiste na apresentação de um estímulo escrito para ser completado com palavras, pode ser uma palavra, uma sentença, um parágrafo, uma imagem (Vergara, 2008). Pela Técnica de Complemento objetivamos identificar motivações, crenças, discursos, sentimentos que dizem respeito ao objeto estudado. Em nosso caso, solicitamos aos professores que completassem sentenças solicitadas.

Também utilizamos entrevistas semiestruturadas com os seis professores de Matemática. Bauer e Gaskell (2003) compreendem que toda pesquisa com entrevistas caracteriza-se como um processo social, uma interação ou um empreendimento cooperativo, em que as palavras são o meio principal de troca. Não é apenas um processo de informação de mão única passando do entrevistado para o entrevistador. Ao contrário, ela é uma interação, uma troca de ideias e de significados, em que várias realidades e percepções são exploradas e desenvolvidas. A entrevista semiestruturada possui a função de complementar as informações que são trocadas e ampliar os ângulos de observação, possibilitando uma maior aproximação da perspectiva dos sujeitos, na tentativa de conhecer suas percepções, aspirações, vontades e atitudes, ou seja, os significados atribuídos à realidade e às suas próprias ações (Lüdke; Adriano, 2006).

A entrevista semiestruturada contém os temas que serão abordados, mas a ordem e a forma como eles serão trabalhados é livre, havendo um guia geral para a entrevista, com algumas perguntas que serão introduzidas na conversa e outras que podem ser acrescentadas, caso as que 


\section{(totherarius Den

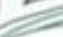

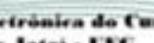

$$
\text { v.11, n. } 1,2015
$$

já foram abordadas pelo entrevistador não sejam respondidas (Salvador, 2002). Esta etapa foi gravada em áudio e as respostas transcritas posteriormente, com a autorização consciente e assinada dos participantes de nossa investigação. Na divulgação dos resultados, foi garantida a privacidade de cada participante, para que eles pudessem expor posicionamentos pessoais.

Metodologia de análise dos dados

A etapa das análises consiste num importante momento da pesquisa e tem como seu principal objetivo "procurar sentidos e compreensão. O que é realmente falado constitui os dados, mas a análise deve ir além da aceitação deste valor aparente. A procura é por temas com conteúdo comum e pelas funções destes temas" (Gaskell, 2008, p. 84).

A partir de três unidades de análise, previamente estabelecidas, organizamos as análises das respostas dos seis professores, que doravante serão denominados P1, P2, P3, etc., procurando identificar relações entre as unidades, com a intenção de compreender melhor o que eles pensam e como organizam suas ações com vistas a apresentação de temas que geram tensão, neste caso específico, probabilidade. As unidades ficaram assim organizadas: a natureza dos obstáculos, as fontes para o surgimento de obstáculos e as atitudes dos professores de Matemática em situações de tensão. Antes de iniciarmos a entrevista, acontecia uma conversa informal com cada professor, com o intuito de diminuir o nervosismo que a própria situação trazia. No decorrer da entrevista, procuramos assumir uma postura de interesse, atenção e compreensão pelas respostas do professor, permitindo que ele se sentisse à vontade para responder e falar livremente dos seus pontos de vista. As respostas foram gravadas em áudio e transcritas posteriormente. A terceira e última etapa foi identificar as atividades desenvolvidas pelos professores, consideradas como práticas para a apresentação do tema probabilidade. Para tanto, também utilizamos a Técnica de Complemento, dividida em duas partes, sendo a técnica de complemento "A" para a existência dos obstáculos no ensino de Matemática, e a "B" para a descrição de uma atividade de iniciação científica.

\section{RESULTADOS E ANÁLISES}

A pesquisa teve início no primeiro semestre de 2014 e aconteceu em sete escolas da rede estadual do munícipio de Tijucas, Santa Catarina. Estabelecemos, como objetivo, analisar a concepção dos professores sobre a natureza de obstáculo, as possíveis fontes para o surgimento 


\section{(2tinerarius Reffectionis:- = 20

de obstáculos e atitudes dos professores em situação de tensão na apresentação do tema probabilidade.

A concepção da natureza de obstáculo

Entendemos que a concepção de obstáculos por parte dos professores de Matemática influenciará, pelo menos em parte, um conjunto de entendimentos, decisões e ações que serão planejadas e trabalhadas em sua prática docente. A "concepção de obstáculo" pressupõe, por parte dos professores, encaminhamentos e decisões sobre como eles compreendem a natureza de obstáculo, os obstáculos no ensino de Matemática, bem como mobilizam os estudantes no desenvolvimento de reflexões durante o seu processo de construção do conhecimento. Apresentamos, em síntese, concepções de obstáculo por parte dos professores de Matemática, organizados em três categorias, de acordo com suas respostas: (1) o obstáculo como impedimento (P1 - P3 - P5 - P6), por exemplo P5, diz que "os obstáculos impedem o desenvolvimento cognitivo do estudante. É como se fosse uma barreira". P1 afirma que "os obstáculos dificultam a passagem do senso comum para o conhecimento científico", (2) o obstáculo com ausência de flexibilidade para novas soluções (conforme P2, "para mim, muitos estudantes só apresentam resultados a partir do caminho, como se fosse único, que o professor apresenta na resolução de uma atividade") e (3) os obstáculos como resíduos do senso comum (diz P4: "os estudantes tem seus conhecimentos oriundos muitas vezes do senso comum, das experiências vivenciadas com suas famílias e amigos, conhecimentos que se enraízam no cerne do conhecimento e de certa forma bloqueia a percepção para novas interpretações").

Percebe-se que existem diferentes concepções de obstáculo, entretanto os professores mencionaram aspectos importantes: preocupação com o desenvolvimento cognitivo, a presença do senso comum na formação de conceitos, conforme P1 e P2. Porém, algumas respostas parecem vagas, como a apresentada por P4: "O estudante possui conhecimento antes mesmo de estar na escola" Os professores P3 e P5 apresentaram uma importante característica de obstáculo: impedimento a ascensão ao conhecimento cientifico, ideia defendida por Bachelard (2008), quando entende que somente é possível a aquisição de um novo conhecimento pelo sujeito quando, no ato de conhecer, houver a superação dos conhecimentos adquiridos anteriormente, carregados de crenças, mitos, de concepções baseadas no senso comum, conhecimentos esses que foram mal estabelecidos, e que já estão sedimentados. P6 menciona que o obstáculo é um 


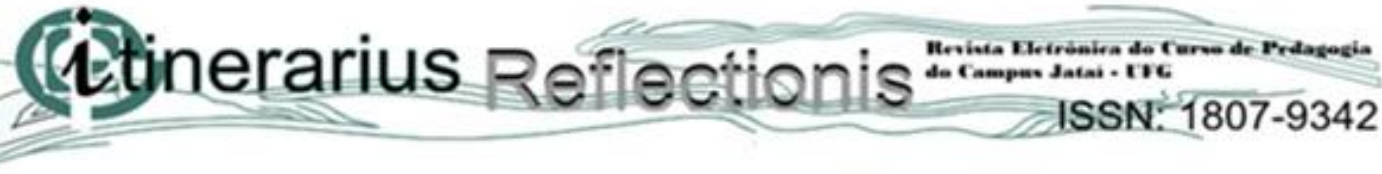

v.11, n. 1,2015

tipo de "trava" que facilita o aparecimento de erros conceituais. Bachelard (2008) defende que os erros surgidos ao longo da construção da ciência, que foram omitidos ou desconhecidos pela história tradicional, podiam auxiliar a detectar os vários obstáculos epistemológicos surgidos ao longo da história da ciência, possibilitando assim, um melhor conhecimento do caminho percorrido pela ciência.

P1, P5 e P6 mencionaram ainda que os obstáculos se apresentam muitas vezes como caráter coletivo, que emerge em questões contextualizadas, onde a maioria da sala apresenta uma concepção baseada na opinião, na tentativa e erro. Na visão de Lecourt (2000), a forma como os professores ensinam Matemática e a relação professor/aluno e conhecimento, muitas vezes por não reconhecer sua construção histórica, evidenciam que as relações existentes entre o conhecimento científico e o senso comum no conhecimento escolar encontram-se desconectadas, como momentos estanques e sem relação. Assim, pode-se dizer que os professores, de certa forma, reconhecem a existência de dificuldades durante o processo de aprendizagem; não destacam o obstáculo como fator preponderante para a apropriação do conhecimento científico, mas valorizam as percepções cristalizadas advindas do senso comum e das experiências vivenciadas ao longo de sua história. As constatações acima evidenciam que o obstáculo, enquanto campo de reflexão coletiva e individual, estão longe de uma concepção mais homogênea e trabalhada no grupo dos professores pesquisados.

\section{Os posicionamentos dos professores e as fontes dos obstáculos}

Acreditamos que o entendimento sobre o reconhecimento das fontes dos obstáculos pelos professores de Matemática durante o ensino de probabilidade é importante para a compreensão de como os obstáculos emergem e como o professor em sua prática pedagógica, se posiciona frente a esse desafio durante o momento de aprendizagem por parte do aluno. Brousseau (2007) cita que a constatação, por parte do professor, de erros e impossibilidades recorrentes entre as diversas turmas, ou recorrentes em um mesmo sujeito, pode ser um forte indício de obstáculo. Um obstáculo não é a ausência de conhecimento, mas um conhecimento, válido em um campo restrito de atuação, o qual se torna obstáculo e/ou motor para outro conhecimento. Assim, apresentamos uma síntese dos posicionamentos dos professores, em suas argumentações, sobre as possíveis fontes de obstáculos. No transcorrer da entrevista, foi possível identificar, por parte dos professores, três fontes de obstáculos. 


\section{(titinerarius 20

A primeira de caráter epistemológico. Conforme P1: "Eu acho que o ensino de probabilidade é um dos temas mais difíceis para os alunos, porque quando o professor induz a generalização desse conceito, leva o aluno a acreditar que a probabilidade é um conceito geral, que não admite situações particulares". Para P4: "quando o aluno não compreende o conceito de universo e evento, torna-se difícil aceitar a relação existente entre possibilidade e probabilidade de ocorrência de um evento". Para Bachelard (2008), a generalização ocorre quando uma lei fica tão clara, completa e fechada, que dificulta o interesse pelo seu estudo mais aprofundado e pelo seu questionamento. Isso significa que leva à imobilidade do pensamento. Brousseau (2007) entende que todas as outras explicações vão derivar desse primeiro conhecimento geral; as mesmas respostas são dadas a todas as questões. São, portanto, generalizações pré-científicas, que podem tornar-se um conhecimento extremamente vago.

Essa primeira fonte confirma os estudos de Bachelard (2008), de que a maioria das pessoas quando acredita fielmente em um assunto, esta ação ofusca o que deveriam saber, impede que o espírito científico seja movido pela problematização, pelo questionamento. Ainda P4 afirmou que "não submeto a psicologia do erro, não admito que meus alunos não aprendam dentro do método didático que aplico. Parece ser o meu primeiro grande ato falho de pensar que o aluno entra vazio de conhecimentos em sala de aula". Bachelard (2008) enfatiza que os alunos carregam consigo uma carga de conhecimentos que acumularam durante sua vida extraclasse, "não se trata, portanto, de adquirir uma cultura experimental, mas sim de mudar de cultura experimental, de derrubar obstáculos já sedimentados pela vida cotidiana. Kummer (1999), por outro lado, recomenda que o conhecimento que os alunos carregam devido à interação com os demais indivíduos de um grupo social, como pais e amigos, não passaram por uma análise crítica, são conhecimentos ametódicos que contemplam apenas várias observações passadas de geração para geração e denomina conhecimento comum, que se opõe ao racionalismo da ciência.

P1 afirmou que "para os alunos a probabilidade envolve corrupção, desvio de dinheiro, jogos de azar, manipulação de resultados”. A partir desse pensamento onde a probabilidade é percebida como elemento hostil, cabe ao professor estimular seus alunos a romperem com o conhecimento comum e mergulhar no conhecimento científico. Para Brousseau (2007), a chave para isso é a problematização. Uma busca de uma boa pergunta sobre aquilo que já está estabelecido. Um novo conhecimento sempre se dá contra um conhecimento já estabelecido. Se o mesmo se mostrar verdadeiro respondendo às perguntas, estará se fortalecendo, caso contrário, 


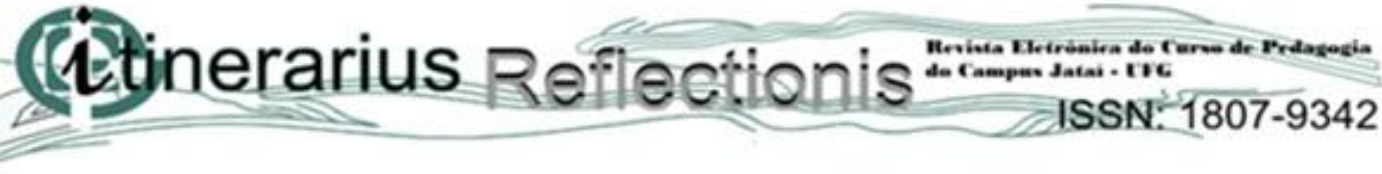

v.11, n. 1,2015

abrirá as portas para o desenvolvimento de um novo conceito. Bachelard (2008) compreende que a experiência primeira ou, para ser mais exato, a observação primeira é sempre um obstáculo inicial para a cultura científica. De fato, esta observação primeira se apresenta repleta de imagens; é pitoresca, concreta, natural, fácil. Basta descrevê-la para se ficar encantado. Parece que a compreendemos.

A segunda fonte é de caráter didático (P2 - P3). P2 afirmou que "a aprendizagem de que a probabilidade é um valor entre 0 e 1, pode ser um obstáculo à aprendizagem de situações onde a probabilidade seja zero (fracasso) do evento ou um (sucesso) do evento". P2 citou um exemplo vivenciado no campo da Geometria: "a dificuldade de ensinar geometria está na utilização da representação por meio de uma perspectiva. Quando utilizo uma atividade sobre uma perspectiva, os alunos demonstram grande dificuldade de compreensão". Para Brousseau (2007), uma das recomendações é não abrir espaço para generalizações precipitadas, sem se atentar para a precisão conceitual. Por outro lado, Bachelard (2008), afirma que a comprovação de um obstáculo didático não passa pelos registros do método histórico crítico.

P3 citou que "o grande desafio do professor de Matemática no ensino de probabilidade é criar um ambiente de investigação, de reflexão sobre os problemas apresentados. Não simplesmente aplicar um macete, certas regras, impedindo o desenvolvimento cognitivo do estudante". Segundo Bachelard (2008), uma ciência que aceita as imagens é, mais que qualquer outra, vítima das metáforas. Por isso, o espírito científico deve lutar sempre contra as imagens, contra as analogias, contra as metáforas. Um ensino que busque, portanto, o desenvolvimento do pensamento científico em seus alunos requer que o professor desloque o pensamento do real “dado" e extraia o máximo possível de abstração no processo de formulação de um problema científico (Brousseau, 2007). Portanto, é importante e até necessário valorizar a crítica, encontrar no pensamento as razões que o impedem de abstrair, portanto descobrir os obstáculos à racionalização da experiência.

Com relação a fonte ontogenética, foi possível perceber nos discursos de P5 e P6, onde afirmam, em linhas gerais, que "muitos alunos chegam no ensino médio sem qualquer embasamento teórico sobre probabilidade. Acredito que muitos professores não apresentam esse tema no ensino fundamental. As dificuldades na resolução de problemas no campo da probabilidade muitas vezes são oriundas da ausência de conhecimento científico sobre o tema". Segundo Bachelard (2008), a observação de casos particulares não serve para fundamentar uma 


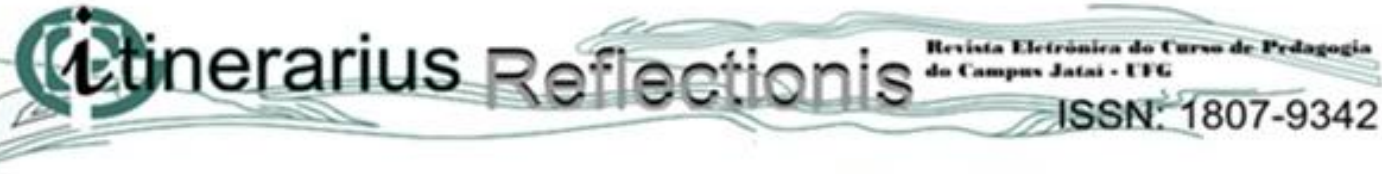

v.11, n. 1,2015

demonstração, no máximo, pode sugerir uma conjectura. No plano escolar, Brousseau (2007) reforça a tese de Bachelard (2008), quando afirma que o risco de ocorrer uma generalização precipitada reside por parte do aluno, na tentativa de transformar o saber cotidiano em saber científico, mas por ter vivenciado experiências vagas, suas asserções encontram-se impregnadas de concepções voltadas mais para saber cotidiano do que para a ciência. Sobre os posicionamentos de P5 e P6, Lukásc (2004) relembra da importância de conhecer os conhecimentos que os estudantes trazem a sala de aula, um espaço privilegiado para debates, reflexão e desenvolvimento do pensamento científico.

As atitudes dos professores investigados em situações de tensão na apresentação do tema probabilidade

$\mathrm{Na}$ trajetória da pesquisa, colocamos em discussão algumas situações de probabilidade que poderiam surgir em sala de aula, mais especificamente nas atitudes inerentes aos assuntos polêmicos do ensino de Matemática e suas respectivas consequências durante processo de ensino e aprendizagem. $\mathrm{O}$ enfoque aqui ficou restrito ao seguinte problema: que atitudes estariam configuradas nas representações dos professores de Matemática ao ensino de probabilidade, diante de questões geradas pelos momentos de tensão, e quais implicações poderão ocorrer no desenvolvimento cognitivo dos estudantes? Poderíamos esperar atitudes múltiplas ou unívocas? Mais do que respostas, buscamos a compreensão das atitudes e representações, ou seja os processos subjacentes de sua construção e as interações histórico-sociais correspondentes.

A respeito das atitudes em situações de tensão na apresentação do tema probabilidade, identificamos duas categorias: (1) o apoio ao uso da probabilidade para jogos de azar (P1 - P3 P6). P1, por exemplo, afirmou que "não vejo problema quando meu aluno pede para abordar a probabilidade nos jogos de azar. É algo natural, se possível, demonstro ainda algumas regras para se dar bem em casas de apostas". Sobre esse posicionamento, Fernandez e Fernandez (2005) relembram que não só o homem comum percebe os acontecimentos indeterminados, mas os homens da ciência igualmente estabeleceram que é necessário, nos fatos de toda natureza, atribuir um significado primordial aos acontecimentos indeterminados. Os homens da ciência deram tal importância aos acontecimentos "aleatórios", isto é, não determinísticos, que foram levados a desenvolver um sistema de cálculo destinado a avaliar estes acontecimentos. Spiegel (2004) considera um experimento aleatório aquele onde o pesquisador não é capaz de conhecer nem controlar o valor de certas variáveis durante a execução do experimento. Este conceito de 


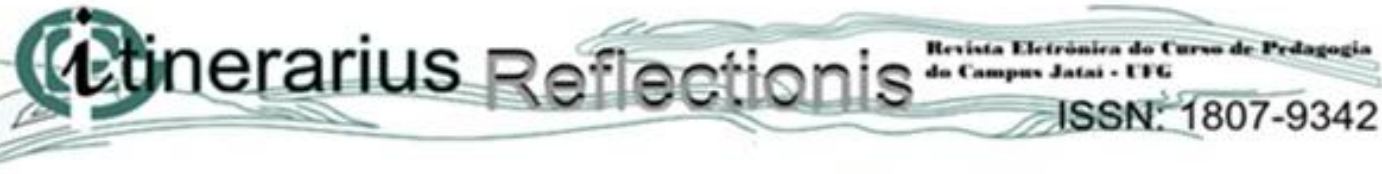

v.11, n. 1,2015

experimento aleatório traz um pouco de determinismo na sua definição, mas, sem dúvida, é o mais adequado para descrever como o que a comunidade científica considera como experimento aleatório. O importante, segundo Echeveste et al. (2004) é que o trabalho com probabilidade na escola deve iniciar com jogos e atividades construtivistas que despertem no aluno o interesse e a curiosidade de resolver os problemas propostos. Experiências com materiais como moedas, bolas, dados, urnas, etc., são uma forma eficaz de familiarizar o aluno com as questões sobre a aleatoriedade de um experimento, bem como trabalhar com os conceitos referentes a eventos possíveis, impossíveis, prováveis, muito prováveis, certos.

Outra categoria que emergiu na entrevista foi: (2) orientação para o não uso da probabilidade em jogos de azar (P2 - P4 - P5). P2 em seu relato, explicou que "hoje muito pouca produção voltada à formação inicial e continuada de professores da educação básica, que vise capacitar para uma atuação mais competente no campo da Educação Estatística, e que portanto, pode levar a tomar decisões equivocadas". P4 afirmou que "é imprescindível o conhecimento estatístico e probabilístico para se fazer uma leitura e um mapeamento da realidade que se vive, da mesma forma que a probabilidade de ocorrência de acontecimentos para agilizarmos a tomada de decisão e fazermos previsões, mas não para enganar ou levar vantagem sobre alguém em alguma aposta". Para Perrenoud (2005), essas considerações conduzem a repensar o papel do professor no processo do ensinar e aprender, sendo necessário que cada profissional tenha consciência de sua ação política através de sua ação pedagógica. D’Ambrósio (2009) salienta que é necessário desenvolver uma prática pedagógica na qual sejam propostas situações em que os estudantes realizem atividades as quais considerem seus contextos e possam observar e construir os eventos possíveis, por meio de experimentação concreta, de coleta e de organização de dados.

Por fim, P5 citou que "o estudo de probabilidade é muito importante, pois desenvolve o raciocínio lógico, a capacidade de abstrair, generalizar, projetar, mas não para levar vantagem sobre os outros, como por exemplo, em compras e jogos". Lopes (2005) relata sobre os Parâmetros Curriculares Nacionais (PCN's) onde o tema probabilidade é muito útil na sociedade atual, devido a necessidade que há dos indivíduos compreenderem as informações veiculadas, fazer previsões que influenciam suas vidas pessoais e em comunidade. Silva (2005) pesquisou sobre a probabilidade no ensino médio e ressaltaram que o ensino da probabilidade no ensino médio pode se constituir em um poderoso instrumento social, na medida em que pode permitir 


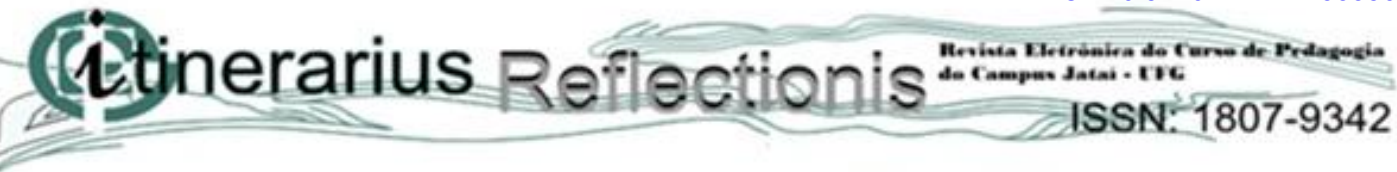

v.11, n. 1,2015

ao estudante uma melhor compreensão das estatísticas, tornando-o capacitado a exercer mais conscienciosamente sua cidadania.

\section{Atividades na apresentação do tema probabilidade}

Com o intuito de aprofundar as concepções dos professores sobre suas estratégias na apresentação do tema probabilidade, solicitamos que apresentassem atividades mencionadas para apresentação do tema probabilidade, descrevendo detalhadamente, seus objetivos, como a atividade era organizada e desenvolvida e quais as atitudes e habilidades vivenciadas pelos estudantes. Entre as atividades descritas, apresentamos um exemplo, relacionado ao tema "probabilidade: uma ferramenta ou arma no campo dos jogos", de acordo com a quadro 1.

Quadro 1: Atividades desenvolvida pelo professor P6, para apresentação do tema probabilidade.

\begin{tabular}{l}
\hline $\begin{array}{l}\text { Atividade apresentada por P6: "probabilidade: uma ferramenta ou arma no campo } \\
\text { dos jogos" }\end{array}$ \\
\hline $\begin{array}{l}\text { OBJETIVO(S): "Identificar e resolver situações-problema que envolvam Probabilidade Simples e } \\
\text { Condicional; Organizar dados e fazer interpretações a partir dos mesmos". }\end{array}$ \\
\hline $\begin{array}{l}\text { ORGANIZAÇÃO E DESENVOLVIMENTO DA ATIVIDADE: "Observação local, conversação } \\
\text { (questionamentos); pesquisa e registros, conversação com quem estuda sobre; conclusão prática, elaboração } \\
\text { de um folder". }\end{array}$ \\
\hline $\begin{array}{l}\text { DESENVOLVE ATITUDES/HABILIDADES? QUAIS? "Creio que sejam desenvolvidas as habilidades de } \\
\text { interpretação, de registros, atitude crítica. Atitudes: mudança de hábitos em relação a probabilidade, } \\
\text { posicionamento crítico ao uso de conceitos de probabilidade". }\end{array}$
\end{tabular}

Fonte: Do pesquisador, 2014.

Podemos perceber que P6 descreve ações importantes, como a observação e a pesquisa, mencionando procedimentos relacionados ao tema, como: "observar as ações das pessoas na tentativa de sucesso em um jogo" e "pesquisar como o é a dinâmica para a formação das possibilidades". Não apresentou os questionamentos que mobilizaram a investigação, porém associou-os à observação do local e às conversas, o que possibilitaria, a partir daí, o desenvolvimento, pelos estudantes, de ações específicas do "fazer ciência mas agir com cautela": problematizar, planejar etapas da investigação, coletar informações e organizar formas de registros, discutir dados, inferir, concluir, comunicar, visando uma compreensão mais aprofundada do fenômeno.

No que diz respeito às atitudes e habilidades, P6 citou a interpretação de registros, a crítica, a mudança de concepção em relação aos jogos de azar e o uso de probabilidade. No item “organização e desenvolvimento da atividade", citou a observação e os registros, e a 


\section{(totherarius 20 yos

"conversação com quem estuda sobre o tema, referindo-se a um especialista", mas não especificou o que exatamente isso significa e como aconteceu. Quando solicitado para descrever como organizou e desenvolveu a atividade, P6 resumiu-a na montagem de atividades envolvendo situações com jogos de azar. Para Gil-Pérez (2005), uma aprendizagem significativa e duradoura é facilitada pela participação dos estudantes na construção do conhecimento científico que está sendo trabalhado. Ressaltamos que os problemas associados à jogos de azar e probabilidade podem ser pontos de partida muito interessantes para introduzir os estudantes no processo, uma vez que eles necessitam ser continuamente desafiados na identificação e resolução problemas, bem como na construção de metodologias para resolvê-los. Evidenciamos que, nesse processo, o registro e a organização dos dados são considerados uma etapa particularmente importante.

\section{CONSIDERAÇÕES FINAIS E CONTRIBUIÇÕES}

Ao finalizarmos este trabalho, podemos tecer algumas considerações a respeito das concepções dos professores de Matemática sobre o tema probabilidade e a construção de um espírito cientifico nas escolas da rede estadual do munícipio de Tijucas.

No que diz respeito ao entendimentos acerca da temática probabilidade, constatou-se que, a maioria dos professores de Matemática apresentam um domínio de representação que engloba, sobretudo, a ideia de que os jogos de azar, as manipulações de resultados e o universo de possibilidades são campos frutíferos para o uso indevido e até inadequado por parte da probabilidade. Entretanto, ao considerarem apenas uma parte dessa realidade, eles deixam de compreender as relações possíveis de uma totalidade. Relações estas que se revelam no avanço de diversos temas como Genética, Economia e Astronomia, com benefícios já comprovados como previsão de sexo para o filho, chances de falência de uma empresa e possibilidade de existência de novas teorias, etc.

Apesar de os professores apresentarem certo posicionamento sobre a existência de obstáculos durante a construção do conhecimento científico, as evidencias apontam para uma fragmentação com relação as possíveis fontes para o surgimento desses obstáculos. Além disso, a maioria dos professores considera que os obstáculos emergem como resultados de fragilidades que os alunos apresentam sobre o tema, didáticas inadequadas escolhidas pelos professores com generalizações e incipiente reflexão, ou ainda, pela inerente dificuldade que o tema remete a sua construção histórica. Portanto, os posicionamentos dos professores no tocante a esse tema, os 


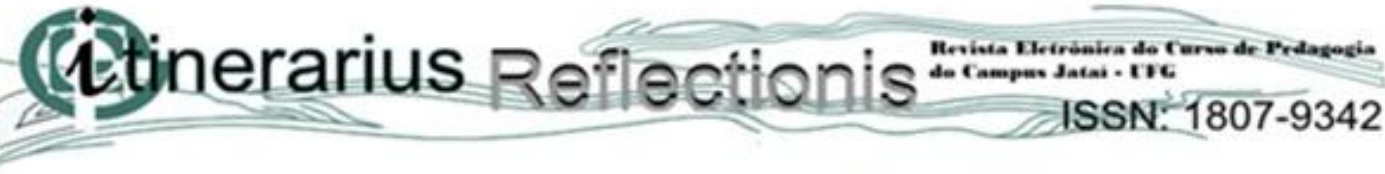

v.11, n. 1,2015

obstáculos e suas fontes durante o processo de construção do conhecimento em sala de aula, se constituem como marcos para discussões e reflexões sobre sua prática docente. Diante dessas representações que refletem o pensamento dos professores, reafirma-se aqui a necessidade da qualificação continuada para que eles possam se aprofundar nessa temática. A reflexão deve ser voltada para a qualificação de conteúdos científicos acerca dos temas na área da Matemática e nas outras áreas do conhecimento.

Os posicionamentos dos professores analisados revelaram, sobretudo, o modo como seus estudantes, ao se posicionar a respeito das transformações, explicita, estrutura e organiza seu conhecimento. Para os professores, os alunos utilizam, essencialmente, suas ideias intuitivas e baseadas na experiência, ao se posicionarem a respeito da probabilidade. Eles deixam evidente que, se compreendem os modelos e ideias teóricas trabalhadas na escola, não sabem como utilizá-los como instrumentos para interpretar os eventos reais (situações-problema) com que se deparam no seu cotidiano.

A análise dos diversos obstáculos mapeados nesse estudo, deixou claro que a incidência do obstáculo epistemológico não é causada pela falta de conhecimento, mas pela existência de um conhecimento que resolve os problemas e que tem utilidade e funcionalidade em determinados contextos, onde ele é capaz de produzir respostas adaptadas a certos problemas. O obstáculo da experiência primeira foi aquele que mais vezes apareceu em nosso trabalho. Sua incidência provavelmente está associada ao conflito existente entre as concepções dos professores a respeito da probabilidade e o conceito que os estudantes possuem em sua estrutura cognitiva.

Para finalizar, alerta-se para a necessidade de um número maior de investigações sobre a temática apresentada neste artigo. Além de preencher lacunas existentes, tais pesquisas contribuiriam para dar maior consistência aos rumos tomados pelo ensino de Matemática, especialmente nos dias atuais com as inserções e discussões cada vez mais crescentes de temas polêmicos em praticamente todas as áreas do conhecimento, sobretudo no campo da ciência e da matemática.

\section{REFERÊNCIAS BIBLIOGRÁFICAS}

BACHELARD, G. A formação do espírito científico: contribuição para uma psicanálise do conhecimento. $3^{\text {a }}$. ed. São Paulo: Contraponto, 2008.

BAUER, M.W.; GASKELL, G. Pesquisa qualitativa com texto, imagem e som: um manual prático. Petrópolis, RJ: Vozes, 2003. 


\section{(atinerarius Refoctons 20 2

$$
\text { v.11, n. } 1,2015
$$

BRASIL. Secretaria de Educação Fundamental. Parâmetros Curriculares Nacionais: terceiro e quarto ciclos do ensino fundamental; Ciências. Brasília: MEC/SEF, v. 4, 1998. Disponível em: <http/portal.mec.gov.br/seb/arquivos/pdf/ciencias.pdf.> Acesso em 9 dez. 2013.

BROUSSEAU, G. A Teoria das Situações Didáticas e a Formação do Professor. Palestra. São Paulo: PUC, 2007.

BRUM, W.P. Crise no ensino de Matemática: os amplificadores que potencializam o fracasso da aprendizagem. São Paulo: Clube de autores, 2014.

COLL, C., et al. O Construtivismo na Sala de Aula. São Paulo: Ática, 2012.

COSTA, R.C. Os Obstáculos epistemológicos de Bachelard e o ensino de ciências. Cad. Educ. FaE/UFPel, Pelotas, v. 11, p. 153-167, 2003.

D'AMBROSIO, U. Educação matemática: Da teoria à prática. $14^{\text {a }}$. ed. São Paulo: Papirus, 2009.

D'AMORE, B. Conceitos de Obstáculos. In: D'AMORE, B. Elementos de didática da Matemática. São Paulo: Editora Livraria da Física, 2007.

DELIZOICOV, D.; ANGOTTI, J. A. P. Ensino de Ciências: fundamentos e métodos. São Paulo: Cortez, 2006.

ECHEVESTE, S.; et al. Formandos de Matemática x Estatística na Escola: Estamos Preparados? Anais do XII Simpósio Sulbrasileiro de Ensino de Ciências. Canoas, 2004.

FERNANDEZ, D.; FERNANDEZ D. O prazer de aprender a probabilidade através de jogos: descobrindo a distribuição Binomial. Experiências e perspectivas do ensino da estatísticadesafios para o século XXI. Florianópolis, 2005.

FREITAS, J. L. M. "Situações didáticas". In : Educação matemática: uma introdução, Série Trilhas, EDUC, p. $65-87,2002$.

FRICKE, R. M.; VEIT, P. S. Educação estatística nos meandros das relações de poder na educação. In: Anais do IX Seminário IASI de Estatística Aplicada "Estatística na Educação e Educação em Estatística”. Rio de Janeiro: Iasi, 2003.

GARBI, G.G. A Rainha das Ciências: um passeio histórico pelo maravilhoso mundo da matemática. $2^{a}$. ed. São Paulo: Livraria da Física, 2009.

GASKELL, G. Entrevistas Individuais e Grupais. In: Bauer, M.W.; Gaskell, G. (Eds.), Pesquisa qualitativa com texto, imagem e som: um manual prático. (pp. 64-89). Petrópolis, RJ: Vozes, 2008. 


\section{Ctinerarius Refochonis 2

$$
\text { v.11, n. } 1,2015
$$

GIL-PÉREZ, D. Importância da educação científica na sociedade atual. In: CACHAPUZ, A., GIL-PÉREZ, D., CARVALHO, A.M.P., VILCHES, A. (Org.), A Necessária Renovação do Ensino de Ciências. (p. 19-34). São Paulo: Cortez, 2005.

GOMES, H. J. Obstáculos epistemológicos no ensino de ciências: um estudo sobre suas influencias nas concepções de átomo. Ciência e Cognição. v. 12, p. 12-45, 2007.

HOUAISS, I.A. Dicionário Houaiss. Versão 2.a (software). Abril, CD-ROM, 2007.

IGLIORI, S. B. C. A noção de obstáculo epistemológico e a educação matemática. In: Educação matemática: uma introdução, Série Trilhas, EDUC, p. 89-113, 2002.

KUMMER, T. Conhecimento, conhecimento científico e conhecimento do senso comum. Revista Roteiro, Ed. UNOESC: v.22, n.42, p. 45-56, 1999.

LECOURT, D. Para uma crítica da epistemologia. Lisboa: Assírio e Alvim, 2000.

LEITE, V. et al. Obstáculos epistemológicos em livros didáticos: um estudo das imagens de átomos. Candombá. Revista Virtual, v. 2, n. 2, p. 72-79, 2006.

LOPES, A.R.C. Contribuições de Gaston Bachelard ao ensino de ciências. Enseñanza de las ciencias, v.11, p. 324-330, 2005.

LOPES, C. A. E. O conhecimento profissional dos professores e suas relações com Estatística e Probabilidade na Educação Infantil. Tese (Doutorado em Educação) - Faculdade de Educação, Universidade Estadual de Campinas, Campinas, 2003.

LÜDKE, M.; ADRIANO, M.E.D.A. Pesquisa em educação: abordagens qualitativas. São Paulo: EPU, 2006.

LUCKESI, C. C. Avaliação da aprendizagem escolar: estudos e proposições. 10a . ed. São Paulo: Cortez, 2000.

LUKÁCS, G. Ontologia del ser social: el trabajo. Buenos Aires: Herramienta, 2004.

MENDES, I. A. O uso da história da matemática: reflexões teóricas e experiências. Belém EDUEPA, 2011.

MORTIMER, E.F. Linguagem e formação de conceitos no ensino de ciências. Belo Horizonte: UFMG, 2000.

PAIS, L. C. Obstáculos epistemológicos e didáticos. In: PAIS, L. C. Didática da Matemática: uma análise da influência francesa. Belo Horizonte: Autêntica, v.3, p. 39-49, 2008.

PERRENOUD, P. Construir competências é virar as costas aos saberes? Revista Pátio, v.1 n. $11,2005$. 


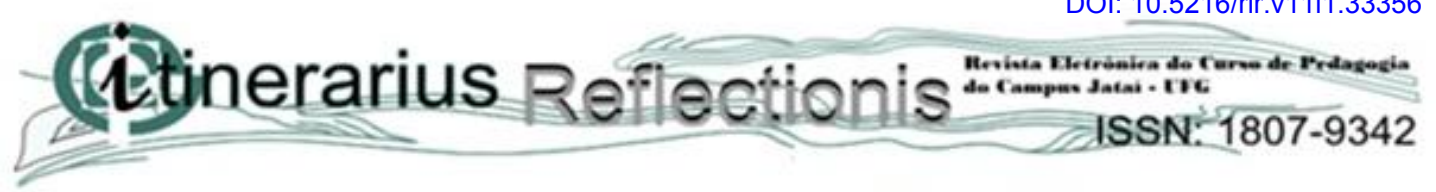

$$
\text { v.11, n. } 1,2015
$$

PIETROCOLA, M. Curiosidade e imaginação - os caminhos nas ciências, nas artes e no ensino. In: Ensino de Ciências: unindo a pesquisa e a prática. São Paulo: Thompson, 2004.

SALVADOR, P.M.P.D. Avaliação do Impacte de Atividades Outdoor: Contributo dos Clubes de Ciência para a Alfabetização Científica. Dissertação (Mestrado em Geologia para o ensino) - Universidade do Porto, Porto, 2002.

SILVA, F. Uma proposta do Ensino da Probabilidade no nível médio. Projeto de final de curso de Licenciatura em Matemática. UERJ, Rio de Janeiro, 2005.

SPIEGEL, M R. R A. Probabilidade e Estatística. 2a . ed. Porto Alegre: Bookman, 2004.

TAKIS, S. Titanic: A Statistical Exploration. The Mathematics Teatcher, v. 92, n.8, 2002.

VERGARA, S.C. Métodos de Pesquisa em Administração. São Paulo: Atlas, 2008.

ZORZAN, A. L. O conhecimento científico em Bachelard. Revista de Ciências Humanas. Frederico Westphalen/RS, v.2, p. 85-100, 2006. 